\title{
American College of Medical Genetics Consensus Statement on Factor V Leiden Mutation Testing
}

\author{
Wayne W. Grody, MD, PhD ${ }^{1}$, John H. Griffin, PhD' ${ }^{2}$, Annette K. Taylor, MS, PhD ${ }^{3}$, Bruce R. Korf, MD, PhD ${ }^{4}$, \\ and John A. Heit, $M D^{5}$ (ACMG Factor V Leiden Working Group)
}

\section{SUMMARY OF ISSUES AND RECOMMENDATIONS}

Issue 1: Which methodology should be used: Factor V Leiden DNA

\section{Recommendation 1}

When appropriate clinical care requires testing for the factor V Leiden allele, either direct DNA-based genotyping or a factor $\mathrm{V}$ Leiden-specific functional assay is recommended. Patients who test positive by a functional assay should then be further studied with the DNA test for confirmation and to distinguish heterozygotes from homozygotes. Patients on heparin therapy or with known lupus anticoagulant should proceed directly to molecular testing if the modified functional assay is not used. When relatives of individuals known to have factor $\mathrm{V}$ Leiden are tested, the DNA method is recommended.

\section{Issue 2: Who should be tested?}

\section{Recommendation 2}

Opinions and practices regarding factor $\mathrm{V}$ Leiden testing vary. Some physicians advocate testing of all patients with venous thrombosis except when active malignancy is present. Others exclude testing in patients over age 60 in the absence of a family history of thrombosis or a previous thrombotic event.

There is growing consensus that testing should be performed in at least the following circumstances (these are the same general recommendations for testing for any thrombophilia):

- Age $<50$, any venous thrombosis.

- Venous thrombosis in unusual sites (such as hepatic, mesenteric, and cerebral veins).

\footnotetext{
From the ${ }^{I}$ Divisions of Medical Genetics and Molecular Pathology, UCLA School of Medicine, Los Angeles, California; ${ }^{2}$ Department of Molecular and Experimental Medicine, Scripps Research Institute, La Jolla, California; ${ }^{3}$ Kimball Genetics, Denver, Colorado; ${ }^{4}$ Division of Genetics and Department of Neurology, Children's Hospital and Harvard Medical School, Boston, Massachusetts; ${ }^{5}$ Department of Medicine, Mayo Clinic and Foundation, Rochester, Minnesota.

Address for reprints: American College of Medical Genetics, 9650 Rockville Pike, Bethesda, MD 20814-3998.
}

- Recurrent venous thrombosis.

- Venous thrombosis and a strong family history of thrombotic disease.

- Venous thrombosis in pregnant women or women taking oral contraceptives.

- Relatives of individuals with venous thrombosis under age 50.

- Myocardial infarction in female smokers under age 50.

Testing may also be considered in the following situations:

- Venous thrombosis, age $>50$, except when active malignancy is present.

- Relatives of individuals known to have factor V Leiden. Knowledge that they have factor V Leiden may influence management of pregnancy and may be a factor in decision-making regarding oral contraceptive use.

- Women with recurrent pregnancy loss or unexplained severe preeclampsia, placental abruption, intrauterine fetal growth retardation, or stillbirth. Knowledge of factor $\mathrm{V}$ Leiden carrier status may influence management of future pregnancies.

Random screening of the general population for factor $\mathrm{V}$ Leiden is not recommended.

Routine testing is not recommended for patients with a personal or family history of arterial thrombotic disorders (e.g., acute coronary syndromes or stroke) except for the special situation of myocardial infarction in young female smokers. Testing may be worthwhile for young patients $(<50$ years of age) who develop acute arterial thrombosis in the absence of other risk factors for atherosclerotic arterial occlusive disease.

Neither prenatal testing nor routine newborn screening is recommended.

\section{Issue 3: Should testing be offered to individuals with environmental risk factors?}

\section{Recommendation 3}

Factor V Leiden testing is recommended in women with venous thromboembolism during pregnancy or oral contraceptive use. In contrast to general screening before administration of oral contraceptives, targeted testing of women with a personal or family history of venous thrombosis is advisable. Routine screening for factor $\mathrm{V}$ Leiden in asymptomatic women 
contemplating or using oral contraceptives is not recommended, except for those with a personal history of thromboembolism or other medical risk factors. Those women with a family history of thromboembolism, APC resistance, or documented factor $\mathrm{V}$ Leiden mutation should be counseled about their risks and options and considered for testing depending on the overall clinical situation. Women with a history of recurrent late-trimester fetal loss should also be considered for testing. Whether or not the woman smokes would not alter these recommendations. Screening of asymptomatic individuals with other recognized environmental risk factors such as surgery, trauma, paralysis, and malignancy is not necessary or recommended, since all such individuals should receive appropriate medical prophylaxis for thrombosis regardless of carrier status.

\section{Issue 4: Should patients found to be positive for factor V Leiden or APC resistance be tested for any of the other heritable thrombophilic risk factors?}

\section{Recommendation 4}

Patients testing positive for factor V Leiden or APC resistance should be considered for molecular genetic testing for the most common other thrombophilias with overlapping phenotype for which testing is easy and readily available. At present, only the prothrombin $20210 \mathrm{~A}$ variant fits these criteria. It is present in $1-2 \%$ of the general population, its involvement in venous thromboembolism is well-established, and the DNA test is as simple as that for factor $\mathrm{V}$ Leiden (with which it can even be multiplexed). Protein S, protein $C$, and antithrombin III deficiencies are too genetically heterogeneous for routine molecular genetic testing, but testing by functional coagulation assays may be considered, especially if there is a strong family history of venous thrombosis. Hyperhomocysteinemia should be considered and tested (in most cases by measuring plasma homocysteine levels) as another potential risk factor in those found to be positive for factor $\mathrm{V}$ Leiden. Patients with classic homocystinuria are at extremely elevated risk of thromboembolism and should probably be tested for other available thrombophilic risk factors.

Issue 5: Should testing for other heritable thrombophilic factors be performed simultaneously with factor $V$ Leiden testing?

\section{Recommendation 5}

Physicians ordering factor V Leiden on a venous thrombosis patient for any of the indications recommended here should also consider the utility of functional, biochemical, and molecular screening for other heritable thrombophilic factors, especially prothrombin 20210A and plasma homocysteine levels.

\section{Issue 6: Are there any other factor $\mathbf{V}$ mutations in addition to factor V Leiden which should be tested?}

\section{Recommendation 6}

The factor V Leiden (R506Q) mutation is currently the only molecular analysis of the factor $\mathrm{V}$ gene indicated in the routine workup of thrombotic risk.

\section{Issue 7: What are the recommended methodologies and quality assurance standards for performing these tests?}

\section{Recommendation 7}

The factor V Leiden mutation test should be performed using any of the accepted technical approaches as long as they have been properly validated by the laboratory, while adhering to current ACMG/CAP quality assurance guidelines for molecular genetic testing.

\section{Issue 8: What are the appropriate pre- and postanalytic procedures to be followed in factor V Leiden testing?}

\section{Recommendation 8}

Formal informed consent should not be required for factor V Leiden testing, but individuals being tested should be made aware that this is a genetic test, that test results have implications about risk in other family members, and that there may be attendant issues of confidentiality and possible insurance discrimination. The laboratory's report should state explicitly the relative risk implications for factor V Leiden heterozygotes and homozygotes, the risk that other relatives may have the mutation, and the recommendation, if indicated, for testing for other inherited hypercoagulabilities.

It is important for individuals testing positive for factor $\mathrm{V}$ Leiden to understand the risk implications and genetic implications of their result. Patients should be counseled about these implications by their physician or genetic counselor.

\section{BACKGROUND}

Normal hemostasis requires a delicate balance between the natural procoagulant and anticoagulant systems. Both of these systems are subject to disruption by either inherited or acquired (including both intrinsic and environmental) defects. Inherited defects associated with clinical bleeding disorders (e.g., hemophilia A and B and von Willebrand disease) have been known and studied for centuries. In contrast, inherited defects causing thrombosis have been recognized more recently. These heritable thrombophilias (hypercoagulabilities) include factor V Leiden (R506Q mutation), the prothrombin 20210A mutation, antithrombin III deficiency, and deficiencies of protein $\mathrm{C}$ and protein $\mathrm{S}$.

The incidence of venous thrombosis is about 1 per 1,000 person-years ${ }^{1}$ and leads to 50,000 deaths annually in this country. $^{2}$ It is a multifactorial disorder, involving one or a combination of genetic risk factors and acquired or environmental 
conditions such as pregnancy, oral contraceptive use, estrogen therapy, malignancy, stroke with extremity paresis, trauma, surgery, or immobility. ${ }^{3}$ The risk increases with the number of genetic and/or environmental conditions present, though venous thromboembolism can occur in the absence of known risk factors. Known genetic causes are present in approximately $25 \%$ of unselected venous thrombosis cases and up to $63 \%$ of familial cases. ${ }^{4}$

Factor V R506Q (Leiden), causing activated protein C (APC) resistance, was discovered in 1994 and is the most common genetic risk factor for venous thrombosis. It is present in 5\% of Caucasian Americans, 20\% of idiopathic first venous thrombosis cases, and $60 \%$ of venous thrombosis cases in pregnant women. Knowledge of the presence of factor $V$ Leiden in patients and relatives can influence management and prevention of venous thrombosis in some cases. Factor V Leiden has also been associated with increased risk of recurrent pregnancy loss and placental infarction.

\section{The procoagulant system}

The normal function of the procoagulant system is to target a hemostatic plug containing platelets and fibrin into a breach within the inside lining of "injured" blood vessels. The procoagulant system has been characterized as a "cascade" of amplifying enzymatic reactions leading to the final serine protease, thrombin. The procoagulant system is triggered by exposure of the coagulation activator, tissue factor, to circulating blood. Tissue factor normally is sequestered from the circulation within the wall of blood vessels and only exposed to blood after vessel wall injury. Exposed (or expressed) tissue factor binds circulating factor VII $_{\mathrm{a}}$, and in the presence of anionic phospholipid and divalent cations (e.g., calcium), forms a factor $\mathrm{X}$-ase complex. This factor $\mathrm{X}$-ase complex either directly cleaves ("activates") factor X to $\mathrm{X}_{\mathrm{a}}$, or activates factor IX to IX by limited proteolysis. Factor IX $_{\mathrm{a}}$ binds factor $\mathrm{VIII}_{\mathrm{a}}$ to form a second factor $\mathrm{X}$-ase complex, which activates factor $\mathrm{X}$ to $\mathrm{X}_{\mathrm{a}}$. Factor $\mathrm{X}_{\mathrm{a}}$ binds factor $\mathrm{V}_{\mathrm{a}}$ to form the prothrombinase complex, which activates prothrombin to thrombin. Thrombin produces a hemostatic plug by cleaving fibrinogen to form fibrin monomers, by activation of platelets, and by activating factor XIII to XIII ${ }_{a}$ which crosslinks strands of fibrin monomers to form a stable hemostatic plug. In a feedback amplification loop, thrombin also increases its own production by activating factors V, VIII, and XI. Together factors $\mathrm{V}_{\mathrm{a}}$ and VIII can potentially increase the rate of thrombin generation by one million-fold and provide major control points for the regulation of thrombin generation.

\section{The anticoagulant system}

The function of the natural anticoagulant system is to confine a normal hemostatic plug to the site of vessel wall injury and to prevent the beneficial thrombus from propagating to form a pathologic thrombus, which occludes the lumen of the vessel or embolizes to occlude distant vessels. The recognized anticoagulant components of this system include antithrom- bin III, protein C, and protein S. The anticoagulant system is activated in parallel with the procoagulant system. Protein $\mathrm{C}$ is a circulating vitamin $\mathrm{K}$-dependent zymogen, which is activated to APC, the active enzyme, by the thrombin-thrombomodulin complex. APC functions as a natural anticoagulant by inactivating (via proteolysis) procoagulant factors $\mathrm{V}_{\mathrm{a}}$ and $\mathrm{VIII}_{\mathrm{a}}$ in the presence of protein S. Antithrombin III is a serine protease inhibitor (SERPIN) and acts as a pseudosubstrate to irreversibly inhibit thrombin by covalently binding the thrombin enzymatic active site. The rate of thrombin inhibition by antithrombin III is increased markedly by glycosaminoglycans (e.g., heparin). Familial reductions in plasma antithrombin III, protein $\mathrm{C}$, or protein $\mathrm{S}$ activity due to either reduced plasma protein levels (i.e., altered protein expression), or normal levels of a dysfunctional protein (i.e., altered protein structure), are strongly associated with deep vein thrombosis and pulmonary embolism (venous thromboembolism), and validate the important role of these proteins in the natural anticoagulant system. Altogether, however, the prevalence of these previously recognized familial thrombophilias among venous thromboembolism patients ranges from 5 to $20 \%$, depending on cohort selection. ${ }^{5}$

\section{Activated protein $\mathbf{C}$ resistance and the factor $\mathbf{V}$ Leiden mutation}

The report of three unrelated probands and their families with idiopathic recurrent venous thromboembolism whose plasma was resistant to the anticoagulant effect of exogenously added $\mathrm{APC}^{6}$ has provided exciting new insights into the etiology of venous thromboembolism. Early epidemiologic data suggested that an abnormally low anticoagulant response to APC, termed "activated protein C resistance (APC-R)," was familial, with an autosomal dominant or semidominant inheritance pattern. ${ }^{7}$ Factor $\mathrm{V}_{\mathrm{a}}$ isolated from APC-R patient plasma was resistant to inactivation by APC. ${ }^{8}$ Subsequent work identified a single point mutation (G to A) at nucleotide 1691 of the factor $\mathrm{V}$ gene, which results in substitution of a glutamine for arginine at residue 506 (R506Q), one of three APC cleavage sites (R306, R506, R679). ${ }^{9-13}$ This mutation is known as factor V Leiden. Initial APC cleavage at the R506 position is required for optimal exposure and subsequent rapid inactivation of factor $\mathrm{V}$ by APC cleavage at positions R306 and R679. ${ }^{14,15}$ Depending on the APC resistance functional assay used and the cut-off values for defining an abnormal result, the factor V Leiden mutation may account for $85-95 \%$ of patients with APC resistance. Recent studies show that APC-R with normal factor V R506 genotype is a risk factor for venous thrombosis. ${ }^{16,17}$

APC resistance is the most common recognized abnormality of coagulation among patients with venous thromboembolism. The factor V Leiden mutation is carried in heterozygous form by about $5 \%$ of the Caucasian population; it is rarer in Hispanic-Americans, rarer still in African-Americans, and virtually absent in Africans and Asians. ${ }^{18,19}$ It is believed to produce a relative risk of venous thrombosis of about 7-fold in the heterozygous state and about 80 -fold in the homozygous state. It is the most common hereditary thrombophilia and is found 
in roughly $11-20 \%$ of individuals of all ages presenting with their first episode of venous thrombosis. ${ }^{20,21}$ When venous thrombosis patients are selected to be under 50 years old and/or to have recurrent thrombosis, up to $40 \%$ have the factor V Leiden genotype. Because only a single mutation is involved, testing by any number of simple and inexpensive molecular genetic methods is possible.

\section{CHARGE TO THE WORKING GROUP}

Given the high allele frequency of the factor $\mathrm{V}$ Leiden mutation and some of the other inherited thrombophilia defects, questions regarding criteria for testing and the possibility of population screening have been raised. The issues are quite complex and were referred to a specially appointed working group of the ACMG for deliberation. It should be noted at the outset that the group's proposed recommendations as presented here were based on the best scientific evidence available at the time. However, the heritable thrombophilia field is changing rapidly as more clinical studies to further define the genetic risks are completed and additional interacting factors are identified, making the attempt to develop recommendations something of a moving target. As such, these recommendations should be understood as being subject to change as new knowledge accrues.

\section{ISSUES AND RECOMMENDATIONS}

\section{Which methodology should be used: Factor V Leiden DNA testing or functional APC resistance testing?}

APC resistance due to factor $V$ Leiden can be diagnosed by functional analysis of the intrinsic or extrinsic coagulation pathway or by direct molecular genetic testing for the R506Q mutation in the factor $\mathrm{V}$ gene. The coagulation assay for APC resistance is based on a functional analysis of the anticoagulant effect on patient plasma of exogenously added APC. As an anticoagulant, APC normally decreases the rate of thrombin generation in plasma. Available APC resistance assays test for the APC anticoagulant effect via either prolongation of clotting time (e.g., activated partial thromboplastin time [aPTT], prothrombin time [PT], etc.), or by direct measurement of thrombin generation using a chromogenic substrate. The traditional functional test, based on the partial thromboplastin time (aPTT), casts a wider net, since not all cases of clinical APC resistance are due to the factor $\mathrm{V}$ Leiden mutation. However, it lacks specificity for factor $\mathrm{V}$ Leiden and is subject to perturbation by acute phase reactants, pregnancy, oral contraceptives, the acquired lupus anticoagulant syndrome (antiphospholipid antibody), and yet undefined factors. ${ }^{22}$ In addition, it cannot be used in patients receiving heparin or warfarin sodium anticoagulant therapy, and it is much less efficient at distinguishing factor $\mathrm{V}$ Leiden heterozygotes from homozygotes due to extensive overlap in the assay values. Making this distinction is clinically important since homozygotes have about a 10 -fold higher risk of thrombotic events than heterozygotes. A recent modification of the functional assay, involving dilution of patient plasma into factor $\mathrm{V}$-deficient plasma, provides quite reliable differentiation of heterozygotes and homozygotes and little or no interference by the other clinical factors, but narrows the specificity to that of the mutation assay, so that cases of APC resistance due to other causes will be missed. ${ }^{8,23,24} \mathrm{De}-$ spite this drawback, the modified assay has been adopted widely; therefore, any consideration of the relative merits of molecular versus coagulation testing must take this into account.

Other points of comparison between the tests are cost and convenience of specimen handling. Currently, the cost for the DNA test is higher than that for the functional test (though this is likely to change with the advent of new automated DNA technologies). The DNA test requires blood at room temperature, while the APC resistance test requires citrated frozen plasma, which must be prepared using centrifugation.

\section{Recommendation 1}

When appropriate clinical care requires testing for the factor V Leiden allele, either direct DNA-based genotyping or a factor $\mathrm{V}$ Leiden-specific functional assay is recommended. Patients who test positive by a functional assay should then be further studied with the DNA test for confirmation and to distinguish heterozygotes from homozygotes. Patients on heparin therapy or with known lupus anticoagulant should proceed directly to molecular testing if the modified functional assay is not used. When relatives of individuals known to have factor $\mathrm{V}$ Leiden are tested, the DNA method is recommended.

\section{Who should be tested?}

Although factor V Leiden is detected in an appreciable percentage of patients, opinions differ as to the usefulness of identifying the mutation and the clinical criteria for testing. Testing would clearly be helpful if it identified individuals with increased recurrence risk who could then be considered for longterm antithrombotic therapy. In general, for patients with a first, objectively documented venous thromboembolism, the risk of recurrence is highest during the first 6-12 months after the event, with a cumulative recurrence rate of about $30 \%$ by 8-10 years. ${ }^{25,26}$ Patients with persistent risk factors for venous thromboembolism (e.g., cancer, stroke with extremity paresis, obesity) and patients with idiopathic venous thromboembolism are at highest risk for recurrence. ${ }^{27,28}$ It is not yet clear whether factor V Leiden heterozygosity increases risk of recurrent venous thrombosis. A few studies ${ }^{21,29}$ found increases in recurrence risk of 4- to 5-fold and 2-fold, respectively, but other studies found no increase. ${ }^{30,31}$ Currently, identification of factor $\mathrm{V}$ Leiden heterozygosity does not change the therapeutic approach to venous thrombosis or subsequent prophylaxis in most patients. For patients with recurrent venous thromboembolism, some clinicians recommend lifelong anticoagulation therapy, regardless of whether a genetic risk factor is present, ${ }^{32}$ while other clinicians would test patients to assist in decision-making about indefinite anticoagulant therapy and genetic counseling of patients and their families. 
Despite the reservations listed above, there are several arguments in favor of testing for factor V Leiden. In some circumstances, knowledge of the factor $\mathrm{V}$ Leiden status strongly influences patient management. Testing will identify factor $\mathrm{V}$ Leiden homozygosity in $1.5 \%$ of patients under age 70 with a first episode of venous thromboembolism in the absence of malignancy. ${ }^{33}$ Lifetime antithrombotic prophylaxis should be considered for homozygotes after a thrombotic event. ${ }^{34,35}$ This approach is also the case for venous thrombosis patients heterozygous for both factor $\mathrm{V}$ Leiden and the prothrombin 20210A mutation, which is not an uncommon finding, in whom recurrence risk has been shown to be high. ${ }^{36}$ However, the decision must take into account the coexistence of bleeding tendencies and other contraindications. The risk of major bleeding with chronic warfarin therapy may reach $8 \%$ per year, ${ }^{37}$ and there are no studies which provide good estimates of the absolute risk of venous thromboembolism among homozygous carriers. Thus, we do not know what the true riskbenefit ratio is of life-long warfarin anticoagulation for these patients.

A benefit of identifying the factor $\mathrm{V}$ Leiden mutation in patients with venous thrombosis is that asymptomatic family members can opt to determine whether they are at increased risk for venous thrombosis due to this risk factor. The lifetime risk for venous thrombosis in factor V Leiden heterozygotes is approximately $10 \%{ }^{38}$ and for homozygotes is $>80 \% .{ }^{33}$ Knowledge of factor $\mathrm{V}$ Leiden status in asymptomatic relatives can be useful in guiding antithrombotic prophylaxis during periods of risk, particularly postpartum, ${ }^{39}$ and might allow for heightened awareness of presenting signs of deep vein thrombosis. Female relatives may also wish to know their status before deciding to use oral contraceptives.

Factor V Leiden increases the risk for recurrent fetal loss, possibly due to placental thrombosis. ${ }^{40,41}$ Testing in women with recurrent pregnancy loss may be important, since antithrombotic therapy may be effective in allowing these women to carry a pregnancy to term. ${ }^{42}$ Factor V Leiden has also been associated with increased risk of severe preeclampsia, placental abruption, unexplained intrauterine fetal growth retardation, and stillbirth. ${ }^{41,43,44}$ On the other hand, given that factor $\mathrm{V}$ Leiden-associated thrombophilia is an adult-onset disorder of low penetrance, fetal testing is not indicated. For similar reasons, routine newborn screening for factor $\mathrm{V}$ Leiden is not recommended.

Increasing age is a strong independent risk factor for venous thrombosis, and for this reason, many physicians do not attempt to identify genetic risk factors in elderly patients with venous thrombosis. However, at least two studies have shown that among factor $\mathrm{V}$ Leiden carriers, the first lifetime episode of VTE usually occurs after age 50 years, suggesting that testing for this mutation should not be limited to young patients. ${ }^{38,45}$ In another study, $26 \%$ of men over age 60 with a first episode of idiopathic venous thromboembolism had factor V Leiden. ${ }^{21}$

The weight of currently available evidence suggests that arterial thrombosis, myocardial infarction, and stroke are not associated with factor V Leiden. ${ }^{21}$ An exception is myocardial infarction in young ( $<45$ years old) female smokers, in whom the combination of the two factors increases the relative risk 32 -fold. ${ }^{46}$ Factor V Leiden has also been implicated in younger adults $(<50)$ who develop arterial thrombosis in the absence of other risk factors for atherosclerotic disease. ${ }^{47,48}$

\section{Recommendation 2}

Opinions and practices regarding factor V Leiden testing vary. Some physicians advocate testing of all patients with venous thrombosis except when active malignancy is present. Others exclude testing in patients over age 60 in the absence of a family history of thrombosis or a previous thrombotic event.

There is growing consensus that testing should be performed in at least the following circumstances (these are the same general recommendations for testing for any thrombophilia):

- Age $<50$, any venous thrombosis.

- Venous thrombosis in unusual sites (such as hepatic, mesenteric, and cerebral veins).

- Recurrent venous thrombosis.

- Venous thrombosis and a strong family history of thrombotic disease.

- Venous thrombosis in pregnant women or women taking oral contraceptives.

- Relatives of individuals with venous thrombosis under age 50.

- Myocardial infarction in female smokers under age 50.

Testing may also be considered in the following situations:

- Venous thrombosis, age $>50$, except when active malignancy is present.

- Relatives of individuals known to have factor V Leiden. Knowledge that they have factor V Leiden may influence management of pregnancy, and may be a factor in decision-making regarding oral contraceptive use.

- Women with recurrent pregnancy loss or unexplained severe preeclampsia, placental abruption, intrauterine fetal growth retardation, or stillbirth. Knowledge of factor $\mathrm{V}$ Leiden carrier status may influence management of future pregnancies.

Random screening of the general population for factor $\mathrm{V}$ Leiden is not recommended.

Routine testing is not recommended for patients with a personal or family history of arterial thrombotic disorders (e.g., acute coronary syndromes or stroke) except for the special situation of myocardial infarction in young female smokers. Testing may be worthwhile for young patients $(<50$ years of age) who develop acute arterial thrombosis in the absence of other risk factors for atherosclerotic arterial occlusive disease. Neither prenatal testing nor routine newborn screening is recommended.

\section{Should testing be offered to individuals with environmental risk factors?}

Some individuals are at increased risk of venous thromboembolism due to environmental exposures, and some of these 
risks are synergistic with factor $\mathrm{V}$ Leiden if both are present, with combined relative risk values many times higher than those for either condition alone. Examples include oral contraceptive use, pregnancy, and estrogen therapy. Patients facing commonly recognized environmental risks such as surgery, trauma, paralysis, and malignancy should be receiving appropriate venous thromboembolism prophylaxis regardless of genetic status. However, involvement of an environmental trigger for venous thrombosis does not preclude the possible presence of factor $\mathrm{V}$ Leiden or other genetic risk factor.

The environmental factor most extensively discussed in this context is oral contraceptive use in women, which produces a 30 -fold increase in thrombotic risk when the factor V Leiden mutation is also present. Some have, therefore, proposed that women contemplating oral contraceptive therapy be screened for factor V Leiden and that counseling be provided and an alternative method of birth control be offered to those who test positive. On the other hand, convincing arguments can be made that widespread screening on such a large population would not be cost-effective based on number of lives actually saved and the increased risk of pregnancy and other complications in those women obligated to turn to other methods of contraception. Despite the popular concept, it remains controversial whether or not smoking while on oral contraceptives increases the relative risk; recent evidence suggests a synergistic effect on risk of myocardial infarction and cerebral thromboembolic stroke, but not on venous thromboembolism, which is the primary phenotype of factor V Leiden. ${ }^{49,50}$

Converting these hypothetical risks into probabilistic numbers is illustrative of the complexities involved in this sort of decision-making. The increased risk of thrombosis caused by oral contraceptive use alone is about 4-fold; in the setting of factor $\mathrm{V}$ Leiden heterozygosity, this risk increases to 30 fold. ${ }^{51,52}$ While these relative risks may seem high, the absolute risk of thrombotic events in this patient population (primarily young women) is quite low. ${ }^{53}$ The baseline incidence of venous thromboembolism in women under age 44 is about 5 events per 100,000 woman-years. Given a mortality rate from venous thromboembolism in this age group of $1 \%$, and the increase in relative risk from 4 -fold to 30 -fold caused by factor V Leiden heterozygosity, it is estimated that the combined risk would produce 15 deaths per million woman-years (compared to 4 deaths per million woman-years caused by oral contraceptives alone). ${ }^{51,54}$ Based on the population frequency of the factor $\mathrm{V}$ Leiden allele, some have estimated that it would require screening as many as 2 million women to prevent one death. ${ }^{54}$ Furthermore, it would result in withholding oral contraceptives from 90,000 carriers identified in the screening process. These women would be obligated to turn to alternative, typically less effective, forms of contraception, with a resulting increase in pregnancy rate and its attendant complications (including, ironically, intrapartum and postpartum venous thromboembolism, as well as preeclampsia, placental abruption, and fetal growth retardation, which are also associated with factor $\mathrm{V}$ Leiden ${ }^{43}$ ). In addition, they would be exposed to all the potential psychosocial and insurance discrimination risks inherent in any genetic screening program.

\section{Recommendation 3}

Factor V Leiden testing is recommended in women with venous thromboembolism during pregnancy or oral contraceptive use. Routine screening for factor V Leiden in asymptomatic women contemplating or using oral contraceptives is not recommended, except for those with a personal or family history of thromboembolism or other medical risk factors. Those women with a family history of thromboembolism, APC resistance, or documented factor V Leiden mutation should be counseled about their risks and options and considered for testing, depending on the overall clinical situation. Women with a history of recurrent late-trimester fetal loss should also be considered for testing. Whether or not the woman smokes would not alter these recommendations. Screening of asymptomatic individuals with other recognized environmental risk factors such as surgery, trauma, paralysis, and malignancy is not necessary or recommended, since all such individuals should receive appropriate medical prophylaxis for thrombosis regardless of carrier status.

\section{Should patients found to be positive for factor V Leiden or APC resistance be tested for any of the other heritable thrombophilic risk factors?}

A growing constellation of heritable thrombophilic factors, some more accurately described as variants or polymorphisms than mutations, are becoming recognized. These include protein $\mathrm{S}$ deficiency, protein $\mathrm{C}$ deficiency, antithrombin III deficiency, the prothrombin 20210A variant, hyperhomocysteinemia, and classical homocystinuria. The allele frequencies of some of these conditions are high enough that combined states of two or even three risk factors have been reported, with synergistic effects on relative risk. ${ }^{55-60}$ Thus, if a patient tests positive for factor $V$ Leiden, it does not exclude the possibility that other genetic risk factors may be at work also. Some of these other defects are as easy to test for as factor V Leiden and can even be multiplexed in a single assay. ${ }^{61-63}$

After factor $\mathrm{V}$ Leiden, the most common of the heritable thrombophilias are the prothrombin 20210A variant and hyperhomocysteinemia. The prothrombin variant is a single nucleotide change in the 3 -untranslated region of the gene that results in elevated circulating prothrombin levels through an unknown mechanism. It is present in $1-2 \%$ of the general Caucasian population and produces a phenotype similar to that of factor V Leiden. It is found in $6-8 \%$ of unselected patients with a first episode of venous thromboembolism. ${ }^{64}$ In addition, it has been associated with myocardial infarction in young women, cerebral vein thrombosis in oral contraceptive users, preeclampsia and other complications in pregnancy, and miscellaneous infarctions at other sites. ${ }^{43,64-67}$ Among patients with a first episode of venous thromboembolism, $10 \%$ of those identified as factor $\mathrm{V}$ Leiden heterozygotes will also have the prothrombin 20210A variant. 
A flurry of recent work has addressed the possible relationship of elevated plasma homocysteine levels with risk of both venous thromboembolic and cardiovascular disease. It has been known for a long time that these are common complications of homocystinuria, an inborn error of metabolism in which homocysteine levels are dramatically increased. Moreover, there is evidence that the risk of such events is heightened in homocystinuric patients who are also factor V Leiden carriers. ${ }^{55}$ More recently a more proportional gradation of risk has been associated with moderate physiologic elevations of plasma homocysteine in otherwise healthy adults, with relative risk beginning to increase as fasting plasma homocysteine concentration exceeds $10 \mu \mathrm{mol} / \mathrm{liter}$.

A product of methionine metabolism, homocysteine is maintained within a narrow range of concentrations through a complex series of reactions involving several enzymes and cofactors (the latter including vitamin $B_{6}$, vitamin $B_{12}$, and folic acid). Levels may rise as a result of subclinical deficiency of any of the enzymes involved, dietary deficiency of one of more of the cofactors, or a variety of other acquired medical conditions and lifestyle factors. ${ }^{68}$ Of the dietary factors, most recent attention has focused on folate intake, which is essential for metabolism of homocysteine via the remethylation pathway, catalyzed by $\mathrm{N},{ }^{5} \mathrm{~N}^{10}$-methylenetetrahydrofolate reductase (MTHFR). Folate supplementation can lower homocysteine levels by enhancing this pathway, even in states of mild relative deficiency, such as that due to a common thermolabile variant $(677 \mathrm{C} \rightarrow \mathrm{T})$ of the MTHFR enzyme found in heterozygous form in $30-40 \%$ of the general population and homozygous form in $10-15 \% .{ }^{69}$ Because folic acid deficiency is also associated with risk of neural tube defects, dietary supplementation on a population-wide basis through fortification of grain products in the U.S. is now in progress; this action may yield secondary benefits on cardiovascular disease incidence as well. Still, the precise relation between hyperhomocysteinemia and cardiovascular disease or venous thromboembolism remains controversial. ${ }^{70-73}$ Homozygosity for the $677 \mathrm{C} \rightarrow \mathrm{T}$ variant increases the risk for hyperhomocysteinemia, which in turn increases the risk of arterial thrombosis; but the variant by itself is not associated with arterial thrombosis in the absence of hyperhomocysteinemia, and is not associated with venous thrombosis in any case. As a simple point mutation (or point polymorphism), the $677 \mathrm{C} \rightarrow \mathrm{T}$ variant is easy to screen for using molecular methods; however, homozygosity for this mutation accounts for only about a third of cases of hyperhomocysteinemia. Therefore, many authorities feel plasma homocysteine measurement is more informative than molecular testing. Hyperhomocysteinemia interacts synergistically with coexisting factor $V$ Leiden to increase the relative risk of venous thrombosis to 20 -fold greater than in individuals without either risk factor. ${ }^{54}$

\section{Recommendation 4}

Patients testing positive for factor V Leiden or APC resistance should be considered for molecular genetic testing for the most common other thrombophilias with overlapping phenotype for which testing is easy and readily available. At present, only the prothrombin $20210 \mathrm{~A}$ variant fits these criteria. It is present in $1-2 \%$ of the general population, its involvement in venous thromboembolism is well-established, and the DNA test is as simple as that for factor V Leiden (with which it can even be multiplexed). Protein S, protein C, and antithrombin III deficiencies are too genetically heterogeneous for routine molecular genetic testing, but testing by functional coagulation assays may be considered, especially if there is a strong family history of venous thrombosis. Hyperhomocysteinemia should be considered and tested (in most cases by measuring plasma homocysteine levels) as another potential risk factor in those found to be positive for factor V Leiden. Patients with classical homocystinuria are at extremely elevated risk of thromboembolism and should probably be tested for other available thrombophilic risk factors.

\section{Should testing for other heritable thrombophilic factors be performed simultaneously with factor V Leiden testing?}

Venous thrombosis is multifactorial, and the presence of more than one genetic risk factor is not uncommon. It could be argued that anyone presenting for factor V Leiden or APC resistance testing because of a thrombotic event already carries a risk factor for recurrent thrombosis even if found to be negative for factor $\mathrm{V}$ Leiden. Recurrent thrombosis carries a significant morbidity and mortality and is readily prevented by oral anticoagulant therapy, though not without significant risk of bleeding events. Therefore, it is important to identify patients at risk but to target anticoagulation therapy to those at highest risk. Such risk stratification is possible through panel testing of several common hereditary thrombophilic factors as well as acquired conditions such as lupus anticoagulant and/or anticardiolipin antibody. Standard functional coagulation assays performed on such patients are useful to detect defects in antithrombin III, protein $\mathrm{C}$, and protein $\mathrm{S}$; consideration should thus be given to supplementing factor V Leiden DNA testing with testing for prothrombin 20210A, biochemical measurement of plasma homocysteine, and functional coagulation assays for antithrombin III, protein C, and protein S.

\section{Recommendation 5}

Physicians ordering factor $\mathrm{V}$ Leiden on a venous thrombosis patient for any of the indications recommended here should also consider the utility of functional, biochemical, and molecular screening for other heritable thrombophilic factors, especially prothrombin $20210 \mathrm{~A}$ and plasma homocysteine levels.

\section{Are there any other factor $\mathbf{V}$ mutations in addition to factor $\mathbf{V}$ Leiden which should be tested?}

Factor V Leiden appears to account for $90-95 \%$ of cases of $\mathrm{APC}$ resistance. Two rare mutations in the factor $\mathrm{V}$ gene have been described and are of dubious clinical significance. Factor V-Cambridge (R306T) is not strongly associated with venous thrombosis in controlled epidemiologic studies. ${ }^{74}$ Factor VHong Kong (R306C) has been found in 1-2\% of Chinese pa- 
tients but does not appear to be associated with APC resistance. ${ }^{75}$

The R2 allele (H1299R, or A4070G) of the factor V gene, associated with a haplotype known as HR2, is present in $10 \%$ of the general population, and early studies indicate that it increases the risk of venous thrombosis in individuals heterozygous for factor $\mathrm{V}$ Leiden an additional 3-fold beyond their already 7 -fold increased risk. ${ }^{76}$ Testing for R2 in factor V Leiden heterozygotes could potentially become useful if further larger studies support these early findings. R2 further reduces the sensitivity for APC in factor V Leiden heterozygotes. ${ }^{77,78} \mathrm{R} 2$ alone, without coinheritance of factor $\mathrm{V}$ Leiden, neither reduces sensitivity for APC nor increases venous thrombosis risk. ${ }^{77,79}$ The $\mathrm{R} 2$ allele is not present in the same haplotype as factor $\mathrm{V}$ Leiden, so it is not possible for factor $\mathrm{V}$ Leiden homozygotes to have the R2 allele.

\section{Recommendation 6}

The factor V Leiden (R506Q) mutation is currently the only molecular analysis of the factor $\mathrm{V}$ gene indicated in the routine workup of thrombotic risk.

\section{What are the recommended methodologies and quality assurance standards for performing these tests?}

When performed properly using standard techniques, the factor V Leiden mutation test has extremely low false-negative and false-positive rates, whether done by restriction endonuclease digestion of PCR amplicons (AMP-FLPs), allele-specific PCR, allele-specific oligonucleotide probe hybridization, or other validated manual or automated methods. The traditional functional APC resistance test has very high sensitivity but suboptimal specificity for factor V Leiden.

\section{Recommendation 7}

The factor $\mathrm{V}$ Leiden mutation test should be performed using any of the accepted technical approaches as long as they have been properly validated by the laboratory, while adhering to current ACMG/CAP quality assurance guidelines for molecular genetic testing.

\section{What are the appropriate pre- and postanalytic procedures to be followed in factor $\mathbf{V}$ Leiden testing?}

Factor V Leiden testing is well established in mainstream medicine and is used by physicians from numerous specialties including hematology, internal medicine, primary care, and obstetrics. It is important that the genetic implications of factor V Leiden DNA test results be explained adequately by the health care professional conveying the test results to the patient.

\section{Recommendation 8}

Specific informed consent should not be required for factor V Leiden testing, but prior to testing, patients should be made aware that this is a genetic test, that test results have implica- tions about risk in other family members, and that there may be attendant issues of confidentiality and possible insurance discrimination. The laboratory's report should state explicitly the relative risk implications for factor $\mathrm{V}$ Leiden heterozygotes and homozygotes, the risk that other relatives may have the mutation, and the recommendation, if indicated, for testing for other inherited hypercoagulabilities.

It is important for individuals testing positive for factor $\mathrm{V}$ Leiden to understand the risk implications and genetic implications of their result. Patients should be counseled about these implications by their physician or genetic counselor.

Approved by the American College of Medical Genetics Board of Directors on October 31, 2000.

(C) AMERICAN COLLEGE OF MEDICAL GENETICS, 2001

9650 Rockville Pike, Bethesda, MD 20814-3998

Phone 301-530-7127, Fax 301-571-1895

\section{References}

1. Silverstein MD, Heit JA, Mohr DN, Petterson TM, O'Fallon WM, Melton LJ. Trends in the incidence of deep vein thrombosis and pulmonary embolism: a 25-year population-based cohort study. Arch Intern Med 1998;158:585-593.

2. Heit JA, Silverstin MD, Lohse CM, Petterson TM, O'Fallon WM, Melton LJ, Hooper C, Evatt B. The factor V R506Q and prothrombin 20210G $\rightarrow$ A mutations as independent risk factors for venous thromboembolism: a population-based case-control study. Thromb Haemost 1999;1229a(Suppl):387.

3. Heit JA, Silverstein MD, Mohr DN, Petterson TM, O'Fallon WM, Melton LJ. Risk factors for deep vein thrombosis and pulmonary embolism: a population-based case-control study. Arch Intern Med 2000;160:809-815.

4. Bertina, RM. Factor V. Leiden and other coagulation factor mutations affecting thrombotic risk. Clin Chem 1997;43:1678-1683.

5. Heijboer H, Brandjes DPM, Buller HR, Sturk A, ten Cate JW. Deficiencies of coagulation-inhibiting and fibrinolytic proteins in outpatients with deep-vein thrombosis. N Engl J Med 1990;323:1512-1516.

6. Dahlback B, Carlsson M, Svensson PJ. Familial thrombophilia due to a previously unrecognized mechanism characterized by poor anticoagulant response to activated protein C: prediction of a cofactor to activated protein C. Proc Natl Acad Sci USA 1993;90:1004-1008.

7. Svensson PR, Dahlback B. Resistance to activated protein C as a basis of venous thrombosis. N Engl J Med 1994;330:517-522.

8. Sun X, Evatt B, Griffin JH. Blood coagulation factor Va abnormality associated with resistance to activated protein C in venous thrombophilia. Blood 1994;83:31203125.

9. Bertina RM, Koeleman BPC, Koster T, Rosendaal FR, Dirven RJ, de Ronde H, van der Velden PA, Reitsma PH. Mutations in blood coagulation factor V associated with resistance to activated protein C. Nature 1994;343:1535-1536.

10. Voorberg J, Roelse J, Koopman R, Buller H, Berends F, ten Cate J, Mertens K, van Mourik J. Association of idiopathic venous thromboembolism with a single pointmutation at Arg506 of factor V. Lancet 1994;343:1535-1536.

11. Greengard JS, Sun X, Xu X, Fernandez JA, Griffin JH, Evatt B. Activated protein C resistance caused by Arg506Gln mutation in Factor Va. Lancet 1994;343:1361-1362.

12. Zoller B, Dahlback B. Linkage between inherited resistance to activated protein C and factor V gene mutation in venous thrombosis. Lancet 1994;343:1536-1538.

13. Kalafatis M, Rand MD, Mann KG. The mechanism of inactivation of human factor V and human factor Va by activated protein C. J Biol Chem 1994;269:31869-13880.

14. Kalafatis M, Bertina R, Rand MD, Mann KG. Characterization of the molecular defect in factor V-R506Q. J Biol Chem 1995;270:4053-4057.

15. Heeb MJ, Kojima Y, Greengard J, Griffin JH. Activated protein C resistance: molec ular mechanisms based on studies using purified $\mathrm{Gln}^{506}$-factor V. Blood 1995;85: 3405-3411.

16. De Visser MC, Rosendaal FR, Bertina RM. A reduced sensitivity for activated protein $\mathrm{C}$ in the absence of factor $\mathrm{V}$ Leiden increases the risk of venous thrombosis. Blood 1999;93:1271-1276.

17. Rodeghiero F, Tosetto A. Activated protein $\mathrm{C}$ resistance and factor $\mathrm{V}$ Leiden mutation are independent risk factors for venous thromboembolism. Ann Intern Med 1999;130:643-650. 
18. Ridker PM, Miletich JP, Hennekens CH, Buring JE. Ethnic distribution of factor V Leiden in 4047 men and women: implications for venous thromboembolism screening. JAMA 1997;227:1305-1307.

19. Gregg JP, Yamane A, Grody WW. The prevalence of the factor V Leiden mutation in four distinct American ethnic populations. Am J Med Genet 1997;73:334-336.

20. Koster T, Rosendaal FR, de Ronde H, Briet E, Vandenbroucke JP, Bertina RM. Venous thrombosis due to poor anticoagulant response to activated protein C. Lancet 1993;342:1503-1506.

21. Ridker PM, Hennekens CH, Lindpaintner K, Stampfer MJ, Eisenberg PR, Miletich JP. Mutation in the gene coding for coagulation factor $\mathrm{V}$ and the risk of myocardial infarction, stroke, and venous thrombosis in apparently health men. N Engl J Med 1995;332:912-917.

22. Shapiro SS. The lupus anticoagulant/antiphospholipid syndrome. Annu Rev Med 1996;47:533-553.

23. Trossaert M, Conard J, Horellou MH, Samama MM, Ireland H, Bayston TA, Lane DA. Modified APC resistance assay for patients on oral anticoagulant. Lancet 1994; 344:1709.

24. Legnani C, Palareti G, Biagi R, Coccheri S, Bernardi F, Rosendaal FR, Reitsma PH, de Ronde H, Bertina RM. Activated protein C resistance: a comparison between two clotting assays and their relationship to the presence of the factor $\mathrm{V}$ Leiden mutation. Br J Haematol 1996;93:694-699.

25. Prandoni P, Lensing AWA, Cogo A, Cuppini S, Villalta S, Carta M, Cattelan AM, Polistena P, Bernardi E, Prins M. The long-term clinical course of acute deep venous thrombosis. Ann Intern Med 1996;125:1-7.

26. Heit JA, Mohr DN, Silverstein MD, Petterson TM, O’Fallon WM, Melton LJ. Predictors of recurrence after deep vein thrombosis and pulmonary embolism: a population-based cohort study. Arch Intern Med 2000;160:761-768.

27. Kearon C, Gent M, Hirsh J, Weitz J, Kovacs MJ, Anderson DR, Turpie AG, Green D, Ginsberg JS, Wells P, MacKinnon B, Julian JA. A comparison of three months of anticoagulation with extended anticoagulation for a first episode of idiopathic venous thromboembolism. N Engl J Med 1999;340:901-907.

28. Schulman S, Granqvist S, Holmstrom M, Carlsson A, Lindmarker P, Nicol P, Eklund S-G, Nordlander S, Lafars G, Leijd B, Linder O, Loogna E, and the Duration of Anticoagulation Trial Study Group. The duration of oral anticoagulation therapy after a second episode of venous thromboembolism. N Engl J Med 1997;336:393-398.

29. Simioni P, Prandoni P, Lensing AWA, Scudeller A, Sardella C, Prins MH, Villalta S, Dazzi F, Girolami A. The risk of recurrent thromboembolism in patients with an Arg506-Gln mutation in the gene for Factor V (Factor V Leiden). N Engl J Med 1997;336:399-403.

30. Rintelen C, Pabinger I, Knobl P, Lechner K, Mannhalter C. Probability of recurrence of thrombosis in patients with and without factor V Leiden. Thromb Haemost 1996 75:229-232.

31. Eichinger S, Pbinger I, Stumpflen A, Hirschl M, Bialonczyk C, Schneider B, Mannhalter C, Minar E, Lechner K, Kyrle PA. The risk of recurrent venous thromboembolism in patients with and without factor V Leiden. Thromb Haemost 1997; 77:624-628.

32. Hyers TM, Agnelli G, Hull RD, Weg JG, Morris TA, Samama M, Tapson VF. Antithrombotic therapy for venous thromboembolism. Chest 1998;114(Suppl):531S560 S.

33. Rosendaal FR, Koster T, Vandenbroucke JP, Reitsma PH. High risk of thrombosis in patients homozygous for factor V Leiden (activated protein C resistance). Blood 1995;85:1504-1508.

34. Bauer KA. Management of patients with hereditary defects predisposing to thrombosis including pregnant women. Thromb Haemost 1995;74:94-100.

35. Bauer KA. Update on thrombophilia. In: Hematology 1999. The American Society of Hematology Education Program Book, 1999:231-235.

36. De Stefano V, Marinelli I, Mannucci PM, Paciaroni K, Chiusolo P, Casorelli I, Rossi $\mathrm{E}$, Leone G. The risk of recurrent deep venous thrombosis among heterozygous carriers of both factor V Leiden and the G20210A mutation. N Engl J Med 1999;341: 801-806.

37. Gitter MJ, Jaeger TM, Petterson TM, Gersh BJ, Silverstein MD. Bleeding and thromboembolism during anticoagulant therapy: a population-based study in Rochester, Minnesota. Mayo Clin Proc 1995;70:725-733.

38. Heit JA, Sobell JL, Silverstein MD, Li H, Sommer SS. Role of the factor V R506Q mutation in venous thromboembolism. Blood 1997;90:149a

39. Lockwood CJ. Heritable coagulopathies in pregnancy. Obstet Gynecol Surv 1999;54: $754-765$

40. Ridker PM, Miletich JP, Buring JE, Ariyo AA, Price DT, Manson JE, Hill JA. Factor $\mathrm{V}$ Leiden mutation as a risk factor for recurrent pregnancy loss. Ann Intern Med 1998;128:1000-1003.

41. Brenner B. Inherited thrombophilia and pregnancy loss. Thromb Haemost 1999;82: 634-640.

42. Eldor A. The treatment of thrombosis during pregnancy. In: Hematology 1999. The American Society of Hematology Education Program Book. 1999:483-490.
43. Kupferminc MJ, Eldor A, Steinman N, Many A, Bar-Am A, Jaffa A, Fait G, Lessing JB. Increased frequency of genetic thrombophilia in women with complications of pregnancy. N Engl J Med 1999;340:9-13.

44. Dizon-Townson DS, Nelson LM, Easton K, Ward K. The factor V Leiden mutation may predispose women to severe preeclampsia. Am J Obstet Gynecol 1996;175:902-905.

45. Ridker PM, Glynn RJ, Miletich JP, Goldhaber SZ, Stampfer MJ, Hennekens CH. Age-specific incidence rates of venous thromboembolism among heterozygous carriers of factor V Leiden mutation. Ann Intern Med 1997;126:528-531.

46. Rosendaal FR, Siscovick DS, Schwartz SM, Beverly RK, Psaty BM, Longstreth WT, Raghunathan TE, Koepsell TD, Reitsma PH. Factor V Leiden (resistance to activated protein C) increases the risk of myocardial infarction in young women. Blood 1997; 89:2817-2821

47. van de Water NS, French JK, Lund M, Hyde TA, White HD, Browett PJ. Prevalence of factor V Leiden and prothrombin variant F20210A in patients age $<50$ years with no significant stenosis at angiography three to four weeks after myocardial infarction. J Am Coll Cardiol 2000;36:717-722.

48. Halbmayer WM, Haushofer A, Schon R, Fischer M. The prevalence of poor anticoagulant response to activated protein $\mathrm{C}$ among patients suffering from stroke or venous thrombosis and among healthy subjects. Blood Coagul Fibrinolysis 1994;5:51-57.

49. Lidegaard O. Smoking and use of oral contraceptives: impact on thrombotic diseases. Am J Obstet Gynecol 1999;180:S357-S363.

50. Farley TM, Meirik O, Chang CL, Poulter NR. Combined oral contraceptives, smoking, and cardiovascular risk. J Epidemiol Community Health 1998;52:775-785.

51. Rosendaal FR. Oral contraceptives and screening for factor V Leiden. Thromb Hae most 1996;75:524-525.

52. Nichols WL, Heit JA. Activated protein C resistance and thrombosis. Mayo Clin Proc 1996;71:897-898.

53. Middeldorp S, Henkens CMA, Koopman ECM, van Pampus ECM, Hamulyak K, van der Meer J, Prins MH, Buller HR. The incidence of venous thromboembolism in family members of patients with factor V Leiden mutation and venous thrombosis. Ann Intern Med 1998;128:15-20.

54. Vandenbroucke JP, van der Meer FJM, Helmerhorst FM, Rosendaal FR. Factor V Leiden. Should we screen oral contraceptive users and pregnant women? BMJ 1996; 313:1127-1130.

55. Mandel H, Brenner B, Berant M, Rosenberg N, Lanir N, Jakobs C, Fowler B, Selgsohn U. Coexistence of hereditary homocystinuria and factor V Leiden: effect on thrombosis. N Engl J Med 1996;334:763-768.

56. Ridker PM, Hennekens CH, Selhub J, Miletich JP, Malinow MR, Stampfer MJ. Interrelation of hyperhomocyst(e)inemia, factor V Leiden, and risk of future venous thromboembolism. Circulation 1997;95:1777-1782.

57. Van Boven HH, Reitsma PH, Rosendaal FR, Bayston TA, Chowdhury V, Bauer KA, Scharrer I, Conard J, Lane DA. Factor V Leiden (FV R506Q) in families with inherited antithrombin deficiency. Thromb Haemost 1996;75:417-421.

58. Koeleman BPC, Reitsma PH, Allaart CF, Bertina RM. Activated protein C resistance as an additional risk factor for thrombosis in protein C-deficient families. Blood 1994;84:1031-1035.

59. Halbmayer WM, Kalhs T, Haushofer A, Beier F, Fischer M. Venous thromboembolism at a young age in a brother and sister with coinheritance of homozygous 20210A/A prothrombin mutation and heterozygous 1691G/A factor V Leiden mutation. Blood Coagul Fibrinolysis 1999;10:297-302.

60. Rosendaal FR. Thrombosis in the young: epidemiology and risk factors. A focus on venous thrombosis. Thromb Haemost 1997;78:1-6.

61. Hessner MJ, Luhm RA, Pearson SL, Endean DJ, Friedman KD, Montgomery RR Prevalence of prothrombin G20210A, factor V G1691A (Leiden), and methylenetetrahydrofolate reductase (MTHFR) C677T in seven different populations determined by multiplex allele-specific PCR. Thromb Haemost 1999;81:733-738.

62. Wisotzkey JD, Bell T, Monk JS. Simultaneous polymerase chain reaction restriction fragment length polymorphism identification of the factor $\mathrm{V}$ Leiden allele and the prothrombin 20210A mutation. Diagn Mol Pathol 1998;7:180-183.

63. Ryan D, Nuccie B, Arvan D. Non-PCR-dependent detection of the factor V Leiden mutation from genomic DNA using a homogeneous invader microtiter plate assay. Mol Diagn 1999;4:135-144.

64. Poort SR, Rosendaal FR, Reitsma PH, Bertina RM. A common genetic variation in the 3'-untranslated region of the prothrombin gene is associated with elevated plasma prothrombin levels and an increase in venous thrombosis. Blood 1996;88: 3698-3703.

65. Rosendaal FR, Siscovick DS, Schwartz SM, Psaty BM, Raghunathan TE, Vos HL. A common prothrombin variant $(20210 \mathrm{G}$ to $\mathrm{A})$ increases the risk of myocardial infarction in young women. Blood 1997;90:1747-1750.

66. Martinelli I, Sacchie E, Landi G, Taioli E, Duca F, Mannucci PM. High risk of cerebral-vein thrombosis in carriers of a prothrombin-gene mutation and in users of oral contraceptives. N Engl J Med 1998;338:1793-1797.

67. Young G, Krohn KA, Packer RJ. Prothrombin G20210A mutation in a child with spinal cord infarction. J Pediatr 1999;134:777-779. 
68. Williams RH, Maggiore JA. Hyperhomocysteinemia. Pathogenesis, clinical significance, laboratory assessment, and treatment. Lab Med 1999;30:468-475.

69. Kang SS, Wong PWK, Susmano A, Sora J, Norusis M, Ruggie N. Thermolabile methylenetetrahydrofolate reductase: an inherited risk factor for coronary artery disease. Am J Hum Genet 1991;48:536-545.

70. Folsom AR, Nieto FJ, McGovern PG, Tsai MY, Malinow MR, Eckfeldt JH, Hess DL Davis CE. Prospective study of coronary heart disease incidence in relation to fasting total homocysteine, related genetic polymorphisms, and B vitamins: the atherosclerotic risk in communities (ARIC) study. Circulation 1998;98:204-210.

71. Jacobsen DW. Homocysteine and vitamins in cardiovascular disease. Clin Chem 1998 44:1833-1843.

72. Brattstrom L, Tengborn L, Lagerstedt C, Israelsson B, Hultberg B. Plasma homocysteine in venous thromboembolism. Haemostasis 1991;21:51-57.

73. Amundsen T, Ueland PM, Waage A. Plasma homocysteine levels in patients with deep venous thrombosis. Arterioscler Thromb Vasc Biol 1995;15:1321-1323.

74. Franco RF, Maffei FH, Lourenco D, Morelli V, Thomazini IA, Piccinato MH, Zago MA. Factor V Arg306 $\rightarrow$ Thr (factor V Cambridge) and factor V Arg306 $\rightarrow$ Gly mutations in venous thrombotic disease. Br J Haematol 1998;103:888-890.
75. Chan WP, Lee CK, Kwong YL, Lam CK, Liang R. A novel mutation of the factor V gene in Hong Kong Chinese. Blood 1998;91:1135-1139.

76. Faioni EM, Franchi F, Bucciarelli P, Margaglione M, De Stefano V, Castaman G, Finazzi G, Mannucci PM. Coinheritance of the HR2 haplotype in the factor V gene confers an increased risk of venous thromboembolism to carriers of factor V R506Q (Factor V Leiden). Blood 1999;94:3062-3066.

77. De Visser MCH, Guasch JF, Kamphuisen PW, Vos HL, Rosendaal FR, Bertina RM. The HR2 haplotype of factor V: effects on factor V levels, normalized activated protein $\mathrm{C}$ sensitivity ratios and the risk of venous thrombosis. Thromb Haemost 2000;83:577-582.

78. Castaman G, Lunghi B, Missiaglia E, Bernardi F, Rodeghiero F. Phenotypic homozygous activated protein $\mathrm{C}$ resistance associated with compound heterozygosity for Arg506Gln (factor V Leiden) and His1299Arg substitutions in factor V. Br J Haematol 1997;99:257-261.

79. Luddington R, Jackson A, Pannerselvam S, Brown K, Baglin T. The factor V R2 allele: risk of venous thromboembolism, factor $\mathrm{V}$ levels and resistance to activated protein C. Thromb Haemost 2000;83:204-208.

This statement is designed primarily as an educational resource for medical geneticists and other health care providers to help them provide quality medical genetic services. Adherence to this statement does not necessarily ensure a successful medical outcome. This statement should not be considered inclusive of all proper procedures and tests or exclusive of other procedures and tests that are reasonably directed to obtaining the same results. In determining the propriety of any specific procedure or test, the geneticist should apply his or her own professional judgment to the specific clinical circumstances presented by the individual patient or specimen. It may be prudent, however, to document in the patient's record the rationale for any significant deviation from this statement. 